\title{
Web-enquête douleur auprès des internes sur le site www.institut-upsa-douleur.org
}

\section{Pain management internet survey of resident doctors using the website www.institut-upsa-douleur.org}

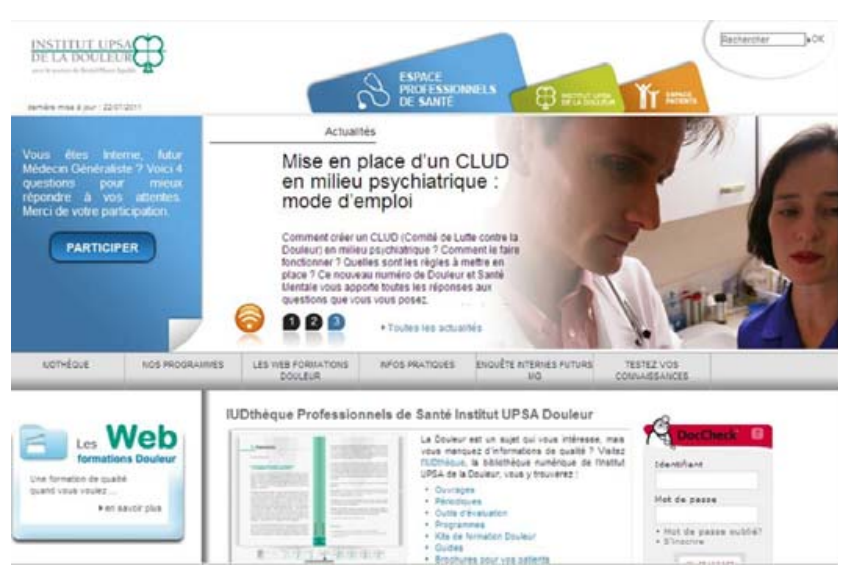

Prise en charge de la douleur, formation, outils, recherche, communication, tels sont les thèmes de la web-enquête menée par l'institut Upsa de la douleur auprès des internes sur son site Internet.

En ligne depuis mi-mai 2011, les premières données recueillies montrent des résultats, quant à la problématique de la prise en charge de la douleur, qui rejoignent ceux du rapport d'évaluation du Plan douleur 2006-2010 par le Haut Conseil de la Santé Publique.

En effet, les internes, dans leur pratique quotidienne, déclarent que, pour eux, la prise en charge de la douleur est problématique, notamment dans les domaines de la gériatrie et de la psychiatrie, ainsi qu'en cancérologie et en soins palliatifs (Fig. 1).

Par ailleurs, il semblerait que la formation assurée par le module 6 (douleur et soins palliatifs) ne soit pas suffisante pour les internes ayant répondu au web-questionnaire (en moyenne $1,9^{1}$ ).

Sur Internet, $88 \%$ des internes ayant répondu au webquestionnaire recherchent de l'information sur la douleur et plus particulièrement sur les traitements $(87 \%)$ et les recommandations $(73 \%)$ versus seulement $40 \%$ sur les pathologies et les comptes rendus de congrès. Cette recherche

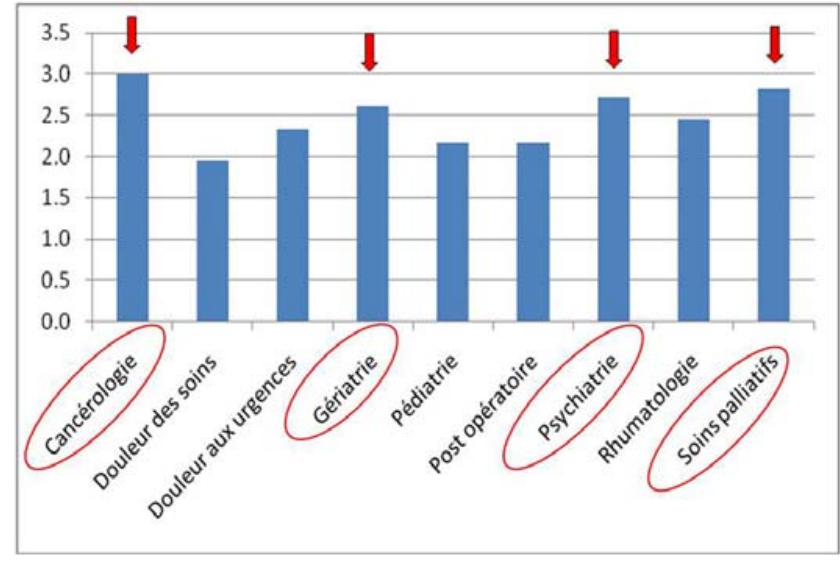

Fig. 1 Réponse à la question $\mathrm{n}^{\mathrm{o}} 1$ de la web-enquête menée sur le site Internet de l'institut Upsa de la douleur (www.institut-upsadouleur.org) : dans votre pratique quotidienne, dans quel domaine la prise en charge de la douleur est-elle problématique ?

d'informations sur la douleur leur est destinée, mais elle est aussi pour $53 \%$ d'entre eux une source sûre d'information pour l'indiquer à leurs patients. Quatre-vingt-cinq pour cent de ces internes recherchent de l'information sur la douleur sous forme d'ouvrages versus $38 \%$ sous forme de diaporama et d'imagerie, $31 \%$ sous forme d'e-learning et $23 \%$ sous forme d'échanges avec des confrères.

Enfin, $82 \%$ des répondants à cette web-enquête souhaiteraient accéder via Internet à des outils d'information et/ou pédagogiques pour communiquer auprès de leurs patients et $53 \%$ pensent que ces informations seraient également utiles sur un support mobile.

L'institut Upsa de la douleur va donc tenir compte de ces premiers résultats en poursuivant sa mission d'information et de formation, notamment avec l'édition d'ouvrages et de publications facilement accessibles via son site Internet : www.institut-upsa-douleur.org, et développer de nouveaux outils.

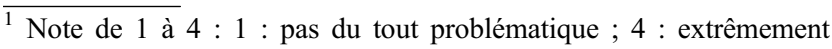
problématique.
} 